\title{
Obesity: a new trend for reporting deaths
}

\section{Editorial}

It is true that death from diseases associated to obesity is on the rise in many regions of the world, particularly cardiovascular diseases. As health care practitioners dealing with obesity and its consequences, this challenging situation should be faced in order to identify strategies to ameliorate it. Energy balance alterations are common nowadays, and physical inactivity was identified as the fourth leading risk factor for global mortality by the World Health Organization in $2010,{ }^{1}$ and the contribution of the alterations in dietary patterns in modern societies to the obesity epidemic has been widely reported by evidence based literature. ${ }^{2}$ The fact that obesity might not be identified as the ultimate cause for disease and in many cases not even be accepted as a disease in spite of the inclusion of obesity as a chronic disorder by WHO in many of its reports ${ }^{2}$ is definitely a topic for discussion and leads to work toward education and intervention that requires an effort to define obesity as a cause of the disabilities of an individual and therefore the cause for reporting it at least as an associated cause of death for many individuals.

While the main objective to be reached by policy makers is early prevention of obesity and its co-morbidities, it is important the adequate report of the causes of morbidity and mortality in general, in order to identify what are the diseases to be taken care of and the subsequent strategies for prevention. Interestingly, in the last years the developing world's deaths by chronic diseases such as type 2diabetes and coronary heart disease have been increasing; moreover in some countries reports of obesity as the direct cause of death of some individuals in the epidemiologic registry can be observed. The increasing reported mortality rate due to obesity in Venezuela as an example increased from 0.1 per 100,000 inhabitants in 1998 to 3.56 per 100,000 inhabitants in 2011 and guides us into several considerations. ${ }^{3}$ First of all, this is challenging since more common has been the report of the mortality by obesity's associated co-morbidities. ${ }^{4}$

The question to be made now would be: How do we achieve to identify obesity as a direct cause of death? Is it because obesity has been associated with higher risk of premature death? Is the logical thought that if the person would have not been obese, the health scenario would have been different? What makes the physician that ultimately filed the registry of death to inform that obesity is the principal cause of death? Is the improvement in the awareness of obesity risks among health care practitioners influencing this reporting? Depending on the circumstances, one could decide that obesity could have been the reason that ultimately was determinant on the death of a person.

From a life cycle perspective, the conclusion that obesity has had a harmful effect over one person's health can be made. How excess weight influences health in the different periods of life, ${ }^{5}$ makes important the report of this chronic disease as a cause of death. As an example, during pregnancy or child birth, the main complications that might end in death are hemorrhage and hypertensive disorders, both definitely associated to lack of adequate care, ${ }^{6}$ but also in the case of the hypertensive disorders during pregnancy (eclampsia) obese mothers are at higher risk to develop this complication and die from it if appropriate care is not given. ${ }^{7}$ What would be the death cause?
Volume 2 Issue I - 2015

\author{
Marianella Herrera Cuenca \\ Nutrition and Food Public Policies, CENDES/Central University \\ of Venezuela, Venezuela
}

Correspondence: Marianella Herrera Cuenca, Nutrition and Food Public Policies, CENDES/Central University of Venezuela, Av. Neveri Ed FUNDAVAC, I Floor, Caracas, Venezuela, Tel 582 I 2753 5859, Email marianella.herrera@ucv.ve

Received: January 30, 2015 | Published: February 05, 2015

And the associated cause? Eclampsia and obesity. Given the interest in the formulation of adequate public actions to prevent premature or unnecessary deaths it is important to assess what causes are related to obesity because there are risk factors that can be prevented.

A study conducted by Flegal et al. ${ }^{8}$ comparing excess death associated with underweight and obesity analyzing data from NHANES I, II and III, shows that underweight and obesity, particularly higher levels of obesity were associated with increased mortality compared to the individuals in the normal weight category. Another interesting finding reported in the same study, is that the impact of obesity on mortality was lower on NHANES II and III than in NHANES I, probably because of the improvements on medical care, public health and the campaigns for obesity prevention. These findings are consistent with the mortality rate reduction in the US from ischemic heart disease. ${ }^{8}$

This situation only highlight that progress regarding diseases associated with the presence of obesity are uneven around the world, while some countries might have been experiencing a decrease in the mortality due chronic diseases including obesity others still are on the rise. An encouragement to report the most reliable and accurate cause of death should be made, in order to keep good records of the situation particularly in the developing world where still many policy makers and health authorities prioritizes under nutrition, when equal attention to both extremes of malnutrition should be given.

A lot of work toward equal and fare distribution of health care are still to be made, adequate nutrition and safety for exercising are to be promoted to guarantee the right to health and food in some populations. When we achieve these interventions equally distributed, we will see an interesting global reduction of death associated or caused by obesity.

\section{Acknowledgements}

None.

\section{Conflict of interest}

Author declares that there is no conflict of interest.

\section{References}

1. World Health Organization (WHO). Global recommendations on physical activity for health. Geneva, Switzerland: World Health Organization Press; 2010. 
2. World Health Organization (WHO). Diet, nutrition and the prevention of chronic diseases. Geneva, Switzerland: World Health Organization technical report series. 2003

3. MPPS. Mortality directories Venezuela, Ministry of Popular Power for Health. 2011.

4. Narayan KM, Ali MK, Koplan JP. Global Noncommunicable DiseasesWhere the Worlds Meet. N Engl J Med. 2010;363(13):1196-1198.

5. Johnson DB, Gerstein DE, Evans AE, et al. Preventing Obesity: A life Cycle Perspective. J Am Diet Assoc. 2006;106(1):97-102.
6. Paxton A, Wardlaw T. Are We Making Progress in Maternal Mortality? $N$ Engl J Med. 2011;364(21):1990-1993.

7. Jeyabalan A. Epidemiology of preeclampsia: Impact of obesity. Nutr Rev. 2013;71(1 Supp):S18-S25.

8. Flegal KM, Graubard BI, Williamson DF, et al. Excess Death Associated With Underweight, Overweight and Obesity. JAMA. 2005;293(15):1861-1867. 